\title{
Nordic Seas nutrients data in CARINA
}

\author{
J. Olafsson ${ }^{1,2}$ and A. Olsen ${ }^{3,4}$ \\ ${ }^{1}$ Marine Research Institute, Skulagata 4, IS 121 Reykjavik, Iceland \\ ${ }^{2}$ Institute of Earth Sciences, University of Iceland, Sturlugata 7, IS 101 Reykjavik, Iceland \\ ${ }^{3}$ Bjerknes Centre for Climate Research, UNI Research, Allégaten 55, 5007 Bergen, Norway \\ ${ }^{4}$ Department of Chemistry, University of Gothenburg, 41296 Göteborg, Sweden
}

Received: 23 February 2010 - Published in Earth Syst. Sci. Data Discuss.: 3 March 2010

Revised: 24 August 2010 - Accepted: 2 September 2010 - Published: 24 September 2010

\begin{abstract}
Water column data of carbon and carbon relevant hydrographic and hydrochemical parameters from 188 cruises in the Arctic, Atlantic, and Southern Ocean have been assembled and the collection merged into a new database: CARINA (CARbon IN the Atlantic). The data have been subject to rigorous quality control (QC) in order to ensure highest possible quality and consistency. The data for most of the parameters included were examined in order to quantify systematic biases in the reported values, i.e. secondary quality control. Significant biases have been corrected for in the data products, i.e. the three merged files with measured, calculated and interpolated values for each of the three CARINA regions; the Arctic Mediterranean Seas (AMS), the Atlantic (ATL) and the Southern Ocean (SO). With the adjustments, the CARINA database is consistent both internally as well as with GLODAP (Key et al., 2004) and is suitable for accurate assessments of, for example, oceanic carbon inventories and uptake rates, and for model validation. The Arctic Mediterranean Seas is the collective term for the Arctic Ocean and the Nordic Seas, and the quality control was carried out separately in these two areas. This contribution presents an account of the quality control of the nutrients (nitrate, phosphate, and silicate) data from the Nordic Seas in CARINA. Out of the 35 cruises from the Nordic Seas included in CARINA, 33 had nutrients data. The nitrate data from 4 of these appeared to be of so poor quality that they should not be used, for phosphate this number is 7 and for silicate it is 3 . We also recommend that the nitrate data from 4 of the cruises should be adjusted, for phosphate and silicate only data from one cruise should be adjusted. The final data appears consistent to $5 \%$ based on evaluation of deep data. For nitrate this corresponds to $0.6 \mu \mathrm{mol} \mathrm{kg}{ }^{-1}$, and for phosphate and silicate it corresponds to 0.04 and $0.6 \mu \mathrm{mol} \mathrm{kg}{ }^{-1}$, respectively.
\end{abstract}

\section{Data coverage and parameter measured}

Repository-Reference:

doi:10.3334/CDIAC/otg.CARINA.AMS.V1.2

Available at:

http://cdiac.ornl.gov/oceans/CARINA/Carina_inv.html

Coverage: $59.60-82.35^{\circ} \mathrm{N}, 35.23^{\circ} \mathrm{W}-28^{\circ} \mathrm{E}$

Location Name: Nordic Seas

Date/Time Start: 1982-02-28

Date/Time End: 2006-02-10

Correspondence to: J. Olafsson (jon@hafro.is)

\section{Introduction}

CARINA (CARbon IN the Atlantic) is a database of carbon and carbon-relevant data from hydrographic cruises in the Arctic, Atlantic and Southern Oceans. The project started as an essentially informal, unfunded project in Delmenhorst, Germany, in 1999 during the workshop on " $\mathrm{CO}_{2}$ in the North Atlantic", with the main goal to create a uniformly formatted database of carbon relevant variables in the ocean to be used for accurate assessments of oceanic carbon inventories and uptake rates. The collection and quality control (QC) of the data have been the main focus of the CARINA project. Both primary and secondary QC of the data has been performed (Tanhua et al., 2010c; Key et al., 2010). The primary QC was carried out by evaluating property-property plots and measurements that showed up as outliers in more than one type of plot were flagged. The secondary QC is described in the present paper. 


\begin{tabular}{|c|c|c|c|c|}
\hline $\begin{array}{l}\text { Data Product } \\
\text { Parameter Name }\end{array}$ & $\begin{array}{l}\text { Data Product } \\
\text { Flag Name }\end{array}$ & $\begin{array}{l}\text { Exchange File } \\
\text { Parameter Name }\end{array}$ & $\begin{array}{l}\text { Exchange File } \\
\text { Flag Name }\end{array}$ & Units \\
\hline station & & STANBR & & \\
\hline day & & DATE & & \\
\hline month & & DATE & & \\
\hline year & & DATE & & \\
\hline latitude & & LATITUDE & & decimal degrees \\
\hline $\begin{array}{l}\text { longitude } \\
\text { cruiseno }\end{array}$ & & LONGITUDE & & decimal degrees \\
\hline depth & & & & meters \\
\hline temperature & & CTDTMP & & ${ }^{\circ} \mathrm{C}$ \\
\hline salinity & sf & SALNTY & SALNTY_FLAG_W & \\
\hline pressure & & CTDPRS & & decibars \\
\hline nitrate & no3f & NITRAT & NITRAT_FLAG_W & micromole $\mathrm{kg}^{-1}$ \\
\hline nitrite & no2f & NITRIT & NITRIT_FLAG_W & micromole $\mathrm{kg}^{-1}$ \\
\hline silicate & sif & SILCAT & SILCAT_FLAG_W & micromole $\mathrm{kg}^{-1}$ \\
\hline phosphate & po4f & PHSPHT & PHSPHT_FLAG_W & micromole $\mathrm{kg}^{-1}$ \\
\hline
\end{tabular}

Parameter list with parameters directly relevant for the nutrient analysis. For a complete list of parameters for the CARINA data base, see (Key et al., 2010). Note the different names for the parameters in the Exchange files (the individual cruise files) and the merged data product.

The CARINA database consists of two parts: the first part is the set of the individual cruise files where all the data reported by the measurement teams are stored. Quality flags are accompanying the data, in many cases these are the flags originally reported, in others they were assigned by R. M. Key, Princeton University (Tanhua et al., 2010c) These files are in WHP (WOCE Hydrographic Program) exchange format where the first lines consist of the condensed metadata. There are essentially no calculated or interpolated values in the individual cruise files, with the exceptions of pressure calculated from depth and some bottle salinities that were taken from ctdsal. No adjustments have been applied to any of the data in the exchange files, with the exception that all $\mathrm{pH}$ measurements were converted to the seawater $\mathrm{pH}$ scale at $25^{\circ} \mathrm{C}$ (Velo et al., 2009).

The second part of CARINA consists of three merged, quality controlled and adjusted data files; one for each of the three CARINA regions the Atlantic Ocean (ATL), Arctic Mediterranean Seas (AMS) and Southern Ocean (SO). These files contain all the CARINA data and also include: (1) interpolated values for nutrients, oxygen and salinity if those data were missing and the interpolation could be made according to certain criteria, as described in (Key et al., 2010); (2); e.g. if total dissolved inorganic carbon $\left(\mathrm{TCO}_{2}\right)$ and total alkalinity (TA) were measured, $\mathrm{pH}$ was calculated; and (3) instances where bottle salinity was missing or bad and was replaced with CTD salinity. Calculated or interpolated values have been given the quality flag " 0 ". In many cases there are additional parameters in the individual cruise files, which have not been included in the secondary QC, such as $\Delta^{14} \mathrm{C}$, $\delta^{13} \mathrm{C}$ and $\mathrm{SF}_{6}$. Many of these are included in the merged data files as well.

This report provides an overview of the nutrient (nitrate, phosphate and silicate) data from the Nordic Seas in CARINA and describes the secondary QC of these data. These data are part of the Arctic Mediterranean Seas subset of CARINA (CARINA-AMS). This subset contains data from the Nordic Seas and the Arctic Ocean. Not one of the cruises of CARINA covered both the Arctic Ocean and the Nordic Seas to the extent that it could be included in the secondary quality control in both regions. In addition, there were no possibilities for crossover comparisons due to scarcity of data in the Arctic Ocean. The data from these regions were therefore analysed separately. The data from the Arctic Ocean are described by Jutterström et al. (2010) while the other Nordic Seas data are described in Jeansson et al. (2010), Falck and Olsen (2009), Olsen et al. (2009) and Olsen (2009a, b). The data acquisition and quality control by use of control charts and certified reference materials, for two time series stations, one of which is in the Iceland Sea and included in CARINAAMS, are described in Olafsson et al. (2010). A more comprehensive description of the complete CARINA database can be found in Key et al. (2010), as well as in the other, more specialised, papers in this special issue.

\section{Data provenance and structure}

The Nordic Seas were loosely defined as the region within the Fram Strait to the north, Greenland to the west, the Greenland-Scotland Ridge to the south, and Norway, the Barents Sea Opening, and Spitsbergen to the east. Out of the 188 CARINA cruises, 62 are included in the CARINA-AMS, and 35 of these considered as Nordic Seas cruises. Five of these are in common with the Atlantic Ocean subset of CARINA and three of those had nutrient data (Tanhua et al., 2010b). The recommendations for these are the same for the Atlantic and Nordic Seas groups, in order to ensure consistency between the regions. Out of the 35 cruises included in the Nordic Seas CARINA, 33 had nutrient data. 
Table 1. CARINA cruises with nutrient data from the Nordic Seas, P-N regression coefficients and recommended multiplicative adjustments for the nutrients.

\begin{tabular}{|c|c|c|c|c|c|c|c|c|}
\hline No. & Expocode & Intercept & Slope & $r$ & $n$ & Nitrate adj. & Phosphate adj. & Silicate adj. \\
\hline 36 & 18HU19820228 & 0.36 & 14.5 & 0.98 & 1754 & 1 & 1 & 1 \\
\hline 67 & $316 \mathrm{~N} 20020530$ & -1.6 & 15.9 & 0.99 & 2060 & 1 & 1 & 1 \\
\hline 78 & 32L919920715 & 2.4 & 11.0 & 0.45 & 122 & $\mathrm{NC}$ & $\mathrm{NC}$ & $\mathrm{NC}$ \\
\hline 79 & 32L919930718 & 7.8 & 5.25 & 0.34 & 83 & $\mathrm{NC}$ & $\mathrm{NC}$ & $\mathrm{NC}$ \\
\hline 91 & 34AR19970805 & -2.6 & 17.7 & 0.97 & 99 & $1.05^{\mathrm{a}}$ & $1.04^{\mathrm{a}}$ & $1.15^{\mathrm{a}}$ \\
\hline 116 & 58AA19940203 & 5.1 & 6.91 & 0.73 & 76 & Flag 3 & Flag 3 & No data \\
\hline 117 & 58AA19940224 & 7.6 & 3.86 & 0.11 & 63 & 1.12 & Flag 3 & No data \\
\hline 118 & 58AA19940826 & -5.5 & 16.5 & 0.89 & 130 & 1.10 & Flag 3 & Flag 3 \\
\hline 119 & 58AA19950217 & 1.7 & 10.7 & 0.75 & 286 & Flag 3 & 1 & 1 \\
\hline 120 & 58AA19961121 & 4.0 & 11.2 & 0.98 & 348 & Flag 3 & Flag 3 & Flag 3 \\
\hline 121 & 58AA19970225 & $\mathrm{NA}^{\mathrm{b}}$ & $\mathrm{NA}^{\mathrm{b}}$ & $\mathrm{NA}^{\mathrm{b}}$ & $0^{\mathrm{b}}$ & Flag $3^{\mathrm{b}}$ & Flag 3 & Flag 3 \\
\hline 122 & 58AA19980308 & -0.48 & 13.4 & 0.92 & 268 & 1 & Flag 3 & 1 \\
\hline 128 & 58GS20030922 & -0.12 & 15.7 & 0.98 & 261 & 1 & 1 & 1 \\
\hline 129 & 58JH19911105 & -0.30 & 15.5 & 0.95 & 347 & 1 & 1 & 1 \\
\hline 130 & 58JH19920712 & 0.72 & 14.2 & 0.83 & 52 & $\mathrm{NC}^{\mathrm{c}}$ & $\mathrm{NC}^{\mathrm{c}}$ & $\mathrm{NC}^{\mathrm{c}}$ \\
\hline 131 & 58JH19921105 & -0.55 & 15.2 & 0.96 & 523 & 1 & 1 & 1 \\
\hline 132 & $58 \mathrm{JH} 19930730$ & -4.4 & 19.1 & 0.97 & 418 & 1 & 1 & 1 \\
\hline 133 & 58JH19931106 & -0.32 & 15.2 & 0.97 & 653 & 1 & 1 & 1 \\
\hline 134 & 58JH19940525 & -4.1 & 17.7 & 0.99 & 452 & 1 & 1 & 1 \\
\hline 135 & 58JH19940723 & -4.7 & 18.4 & 0.92 & 431 & $\mathrm{NC}^{\mathrm{c}}$ & Flag $3^{\mathrm{a}}$ & $\mathrm{NC}^{\mathrm{c}}$ \\
\hline 136 & 58JH19941028 & -0.77 & 15.8 & 0.98 & 1119 & 1 & 1 & 1 \\
\hline 137 & 58JH19950427 & -1.7 & 15.0 & 0.96 & 942 & 1 & 1 & 1 \\
\hline 138 & 58JH19951108 & -0.72 & 15.3 & 0.99 & 450 & 1 & 1 & 1 \\
\hline 139 & 58JH19960720 & -1.8 & 16.5 & 0.99 & 1324 & 1 & 1 & 1 \\
\hline 140 & 58JH19961030 & -0.74 & 15.6 & 0.99 & 330 & 1 & 1 & 1 \\
\hline 141 & $58 \mathrm{JH} 19970414$ & -0.13 & 15.0 & 0.99 & 1140 & 1 & 1 & 1 \\
\hline 142 & 58JH19980801 & -2.7 & 17.4 & 0.97 & 632 & 1 & 1 & 1 \\
\hline 143 & 58JH19990615 & -1.7 & 16.7 & 0.99 & 568 & 1 & 1 & 1 \\
\hline 144 & $58 \mathrm{JH} 20000527$ & -1.4 & 16.1 & 0.99 & 319 & 1 & 1 & 1 \\
\hline 176 & 74JC19960720 & 0.17 & 17.5 & 0.92 & 431 & 0.83 & 1 & 1 \\
\hline 179 & 77DN20020420 & -2.8 & 17.8 & 0.98 & 216 & 1 & 1 & 1 \\
\hline 184 & Iceland Sea TS & -0.37 & 15.3 & 0.93 & 984 & 1 & 1 & 1 \\
\hline 186 & OMEX1NS & -5.6 & 20.2 & 0.99 & 57 & $\mathrm{NC}$ & $\mathrm{NC}$ & $\mathrm{NC}$ \\
\hline
\end{tabular}

a These adjustment factors were derived by the Atlantic group (Tanhua et al., 2009a).

${ }^{\mathrm{b}}$ Nitrate data were flagged 3 during primary QC (Key et al., 2009), hence no regression analysis could be carried out.

${ }^{c}$ Labelled NC because of we felt that the data could not be soundly QC'd given the high hydrographic variability of the area where these data were obtained, the Nordic Seas- North Atlantic overflow regions. See Olsen et al. (2009) for map of station positions of each individual cruise.

Table 1 provides an overview of the data that were included in the secondary quality controls described in this paper, and station positions are shown in Fig. 1.

For reasons of analytical methodology, nitrate is detected along with nitrite. In some of the files these were not reported separately, but as nitrate + nitrite. In such cases it was far from trivial, if not impossible to extract the nitrate and nitrite concentrations. However, given that nitrite is normally only a trace constituent or absent, particularly in oxygenated deep water, we follow here the example for CARINA cruises in the Atlantic and report these data as nitrate, ignoring the possible contribution of nitrite (Tanhua et al., 2010b).

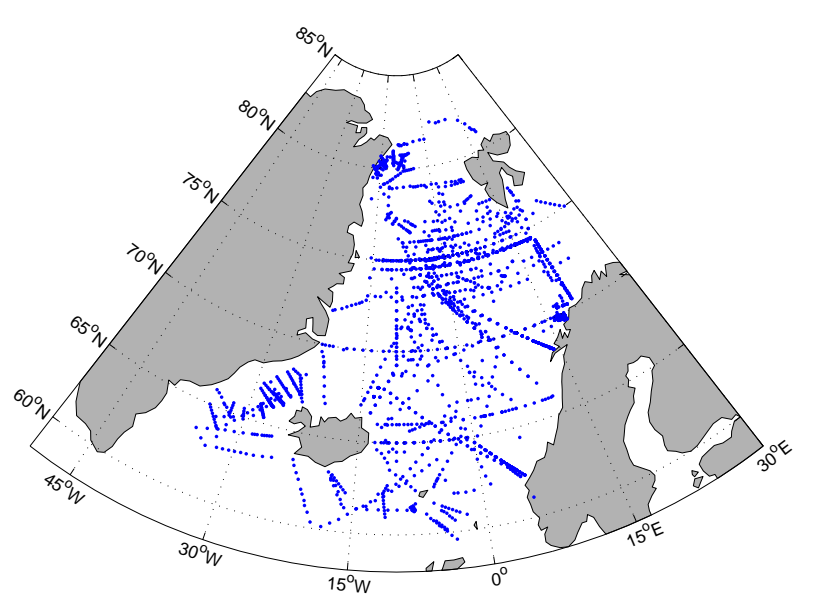

Figure 1. Nordic Seas with nutrient sampling positions. Includes only data retained in CARINA after secondary quality control. 


\section{Quality control methods}

Two methods were used in the secondary quality controll of the data: crossover and inversion analysis and evaluation of phosphate-nitrate (P-N) relationships, these are described in the following two sections. In addition a certain degree of subjective resoning had to be involved, as explained in Sect. 3.3.

\subsection{Crossover and inversion analyses}

The crossover and inversion analysis (Gouretski and Jancke, 2001; Johnson et al., 2001) used to evaluate the consistency of the Nordic Seas nutrients data, was carried out using the version of the cnaX routines (Tanhua et al., 2010c) described by (Olsen et al., 2009). Briefly, the crossover points were found by identifying all station pairs, from different cruises, within $300 \mathrm{~km}$ from each other. Each cruisepair's crossover stations were then further partitioned into at most 6 clusters; groups of data within a circle with a radius of at most $175 \mathrm{~km}$, using a k-means clustering routine (Seber, 1984), each containing at least two stations from each cruise. The data from each station in the cluster were then interpolated into 50-m intervals, and the weighted mean offset and standard deviation for each cruise pair was determined using observations deeper than 1900 dbar. Note that this is deeper than in the other CARINA regions (i.e. $1500 \mathrm{dbar}$ ), in order to avoid effects of ventilation which reached down to 1600 dbar during the 1990s (Ronski and Budeus, 2005). Also note that whereas the crossover analysis is normally carried out using temperature or density as ordinate, depth was used in the Nordic Seas because of the small gradients of both temperature and density in this region.

The offsets and uncertainties from all cruises were used to generate the set of corrections that maximized the consistency between the cruises using a least square model inversion, the weighted least square (WLSQ) inversion of (Johnson et al., 2001), which weights each crossover offset by its standard deviation so that offsets with large uncertainty are less influential than crossovers with small uncertainty. The data from 32L919920715, OMEX1NS and Iceland Sea time series were not included in this analysis because of lack of samples from deeper than $1900 \mathrm{dbar}$. The data from 32L919930718 were not included either, because of the special region covered by this cruise (East Greenland Shelf and Shelf edge, see Fig. 3 of Olsen et al. (2009) for station positions of each individual cruise.). The data from these cruises have been labelled NC (Not considered) in Table 1.

\subsection{Phosphate-Nitrate relationships}

The nutrients are not conservative constituents of sea water. In addition to mixing their concentrations are also affected by biological processes (Redfield et al., 1963). The regional changes in phosphate and nitrate generally follow linear trends in a ratio of $\Delta \mathrm{P}: \Delta \mathrm{N}=1: 16$, the Redfield ratio. The phosphate-nitrate relationships therefore provide an additional tool in the evaluation of nutrient data quality and data adjustments. In the Nordic Seas an account has also to be taken of the nutrient concentration variability associated with water masses. The sea water fluxes through the Nordic Seas include warm northward flowing Atlantic Water, cold and low salinity Polar Water from the Arctic Ocean and, at depth, Arctic- and Arctic Intermediate Waters which flow over the Greenland-Scotland Ridges and contribute to the global ocean thermohaline circulation (Hansen et al., 2008). These different sources result in wide ranges in sea water temperature and salinity and affect also the nutrient relationships. The biochemical changes in the low salinity Polar Water follow a linear Redfield slope pattern, $\mathrm{NO}_{3}=a \mathrm{PO}_{4}+b$, where the slope, $a$, is similar as for Atlantic Water and near the Redfield value, but the intersect, $b$, is significantly lower (Stefansson, 1968; Jones et al., 2003). As an additional QC analysis we therefore examined the nutrients in the CARINA Nordic Seas data set after excluding significant Polar Water influences, select salinity $>34.7$, and select data with quality flags 2 . With this subset of the data the slope of the P-N regression line for good quality data can be expected to lie in the range 15 to 17 and the intercept on the Y-axis (nitrate axis) can be expected to be small and possibly slightly negative if the data has many samples in the low region of this salinity selection.

\subsection{Subjective evaluation}

There are, in general, some instances in works of this kind where decisions have to be made by subjective reasoning. They arise when:

(i) The objective tools provide no results, or

(ii) The results of the objective tools are uncertain.

Class (ii) cases mainly occur if the analysis is carried out in a region with large spatial variability, for instance in the Nordic Seas to North Atlantic exchange and overflow region, or if there are temporal changes, for instance the changes in silicate with time in the deep Greenland Sea. Given this, a consistency analysis cannot and should not be a fully objective excersise, and the results of a crossover analysis or nutrient relationships cannot be blindliy applied. Further analyses may be required, for instance comparing data from cruises carried out close in time, as done here. In addition experiences in working in the Nordic Seas, with data collection, chemical analysis and data interpretation aids in the decision making process. However, it must be emphasized that "expert subjectivity" can never be above doubt. 

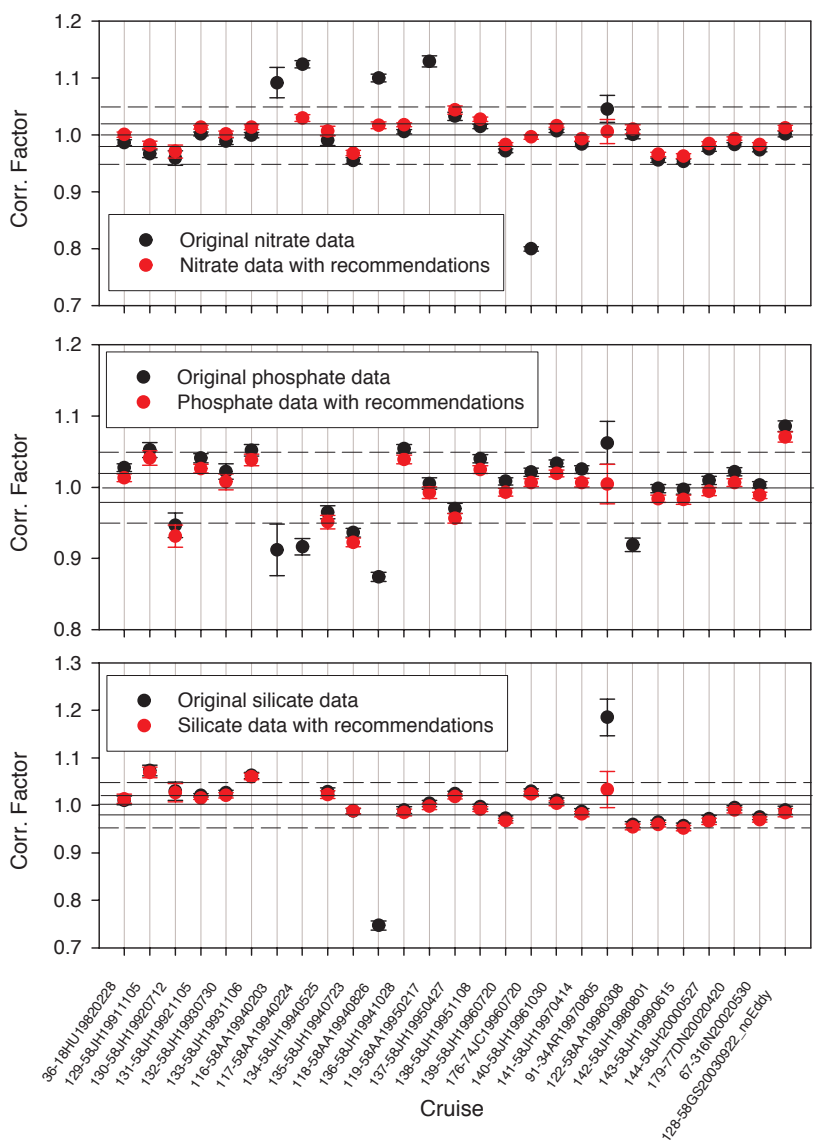

Figure 2. Results of automated crossover and inversion scripts (cna with WLSQ inversion) applied on all cruises in the collection. Dashed lines show 5\% limits. Note that the cruises have been sorted by time in this figure. 58GS20030922 (128) had several stations in a submesoscale coherent eddy (Kasajima et al., 2006), the "noEddy" signifies that these data were removed prior to this analysis.

\section{Results}

The crossover results in themselves can be accessed at the CARINA website (http://cdiac.ornl.gov/oceans/CARINA/ Carina_inv.html). Here we only present the corrections suggested by the WLSQ inversion of the crossover offsets (Fig. 2), and the slope and intercept of the P-N relationships are listed in Table 1. The suggested corrections are multiplicative. The CARINA-wide threshold for considering application of corrections to nutrient data were $2 \%$ (Tanhua et al., 2010b). However, in the deep Nordic Seas, $2 \%$ corresponds to $\sim 0.3 \mu \mathrm{mol} \mathrm{kg}{ }^{-1}$ for nitrate, $\sim 0.02 \mu \mathrm{mol} \mathrm{kg}{ }^{-1}$ for phosphate and $\sim 0.3 \mu \mathrm{mol} \mathrm{kg}^{-1}$ for silicate. These limits are similar to the measurement precision for the nutrients. It was therefore considered more appropriate for the Nordic Seas to set the limits at 5\%. These limits are shown in Fig. 2. For nitrate 5 cruises are outside the $\pm 5 \%$ limits, for phosphate there are 6 cruises outside the $5 \%$ limits and for silicate there are 4 cruises outside the $5 \%$ limits. These cruises are further investigated in the following.

\subsection{Recommendations}

\subsubsection{Nitrate}

For nitrate the following 5 cruises are outside the 5\% limits, 58AA199940203, 58AA19940224, 58AA19940826, 58AA19950217 and 74JC19960720.

\section{Cruise 58AA19940203}

This cruise had only few stations in the northern Greenland Sea. The inversion suggests that these data should be adjusted by a factor of 1.09 . Both $\mathrm{TCO}_{2}$ and TA have been suggested removed from the synthesis product (Olsen, 2009a, b). We see little reason to salvage the nitrate values and suggest that these are flagged 3.

\section{Cruise 58AA19940224}

The inversion suggests that these data are $12 \%$ too low, and the intercept of the PN regression of -4.115 also suggest low nitrate data (Table 1). The exact value of the adjustment factor was determined by comparing the nitrate data of 58AA19940224 with data from previous and subsequent good cruises closest in time (Fig. 3). As evaluated from this figure an adjustment factor of 1.12 appears very reasonable.

\section{Cruise 58AA19940826}

The inversion suggests that these data are $10 \%$ too low. In additon the data has quite large variability at all depths and consequently relatively many observations outside the $\pm 5 \% \mathrm{lim}$ its. The P-N regression slope is within Redfieldian expectations but the intercept, -5.47 , is very low suggesting systematically low nitrate or high phosphate (Table 1). The value of the adjustment factor was further evaluated by comparing the nitrate data of 58AA19940826 with data from previous and subsequent good cruises (Fig. 4). Data selection have been limited to Norwegian Sea where most of the 58AA19940826 cruise was carried out. There is not much data, but the $10 \%$ adjustment appears reasonable.

\section{Cruise 58AA19950217}

The inversion suggested that the nitrate data from this cruise was $13 \%$ too low and the P-N regression slope, 10.6, is unrealistic (Table 1). The data show considerable scatter in addition to the offset. Since both TCO2 and TA have been suggested removed from the synthesis (Olsen, 2009a, b), we see very little reason to salvage these data and suggest that they are flagged 3 .

\section{Cruise 74JC19960720}

The inversion suggested that the nitrate data from this cruise was $20 \%$ too high. This result is supported by the rather high P-N slope with its slightly positive intercept (Table 1). The 

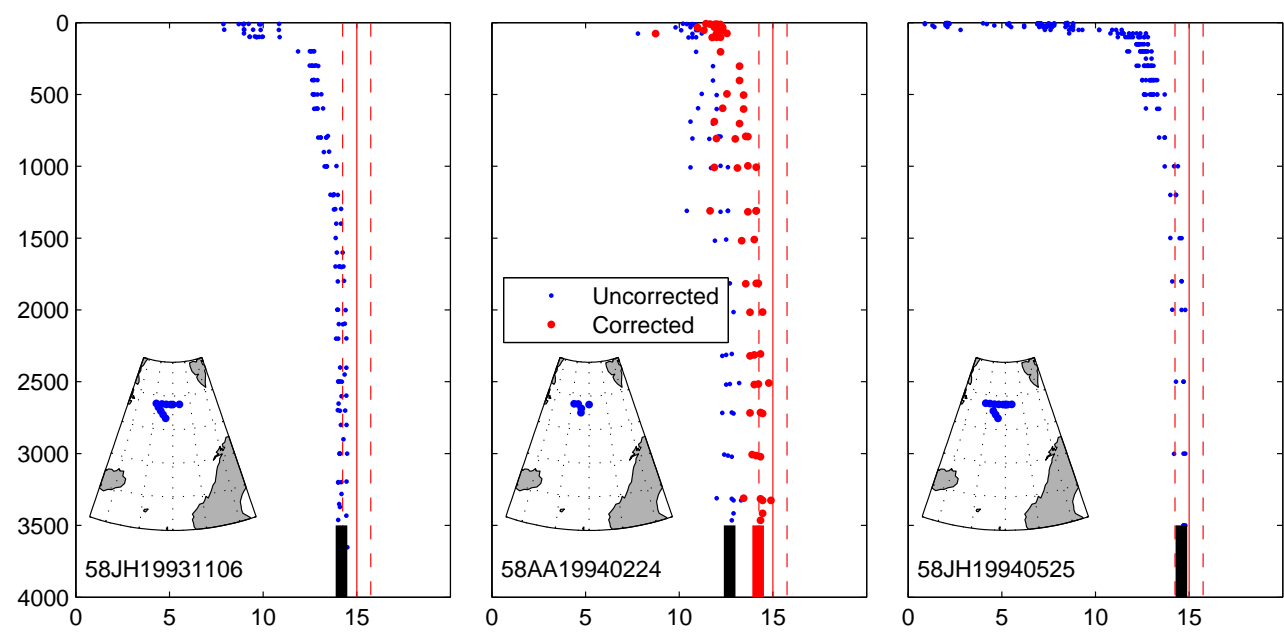

Figure 3. Greenland Sea $\left(73-80^{\circ} \mathrm{N}, 10^{\circ} \mathrm{W}\right.$ to $\left.5^{\circ} \mathrm{E}\right)$ nitrate profiles from 58AA19940224 with (red) and without (blue) corrections applied, along with data from the previous and subsequent cruises. The thick vertical bars at bottom show mean values deeper than 1900 dbar. For reference, red solid and dashes lines have been drawn at $15 \mu \mathrm{mol} \mathrm{kg} \mathrm{kg}^{-1} \pm 5 \%$.
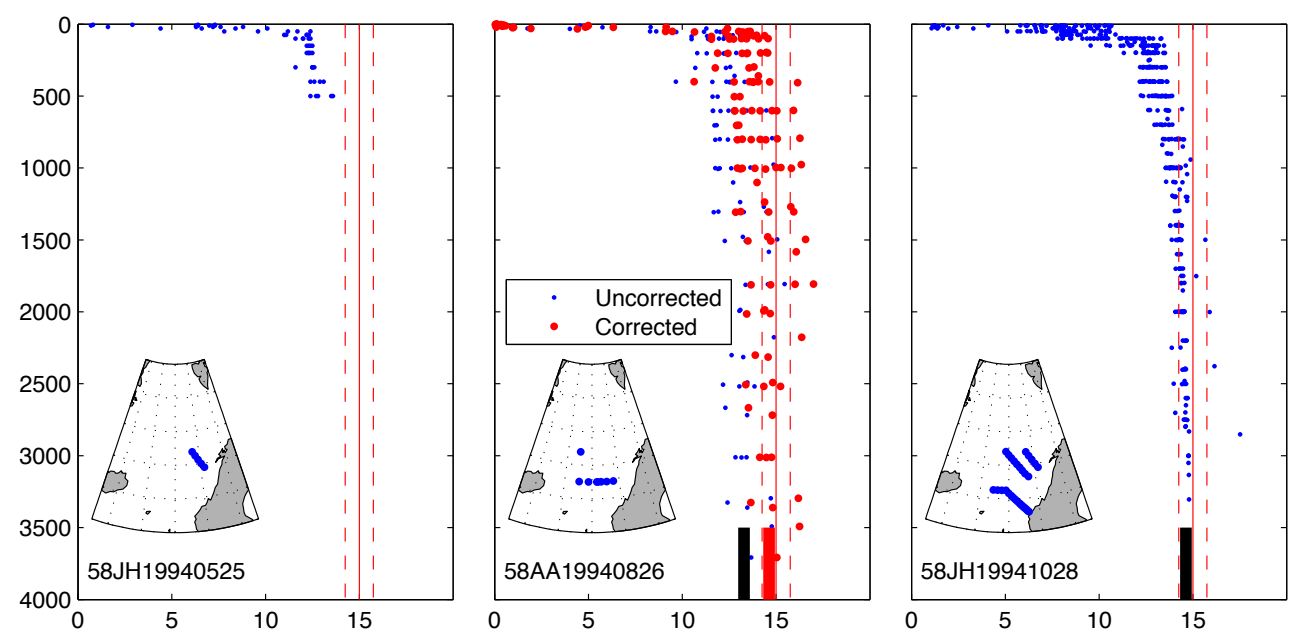

Figure 4. Norwegian Sea $\left(61-70^{\circ} \mathrm{N}, 5^{\circ} \mathrm{W}\right.$ to $\left.10^{\circ} \mathrm{E}\right)$ nitrate profiles from 58AA19940826 with (red) and without (blue) corrections applied, along with data from the previous and subsequent cruises. The thick vertical bars at bottom show mean values deeper than 1900 dbar. For reference, red solid and dashes lines have been drawn at $15 \mu \mathrm{mol} \mathrm{kg}^{-1} \pm 5 \%$.

value of the adjustment factor was further evaluated by comparing the nitrate data of 74JC19960720 with the data from previous and subsequent good cruises closest in time. Based on this analysis the adjustment factor of 0.8 appeared somewhat large (deep mean hitting the $-5 \%$ limit), whereas 0.83 appeared reasonable (Fig. 5) Thus 0.83 is the recommended correction factor for these data.

The recommended nitrate adjustments are summarized in Table 1.

\subsubsection{Phosphate}

For phosphate the following 6 cruises are outside the 5\% limits: 58AA19940203, 58AA19940224, 58JH19940723,
58AA19940826, 34AR19970805, 58AA19980308 and 58 GS2000309.

\section{Cruise 58JH19940723}

This cruise was carried out across the Greenland-Scotland Ridge (see Fig. 3 of Olsen et al. (2009) for station positions of each cruise), a highly variable water mass region and outside the core area of the crossover analyses. Given this we have normally chosen to label data from this cruise (as well as from cruise 58JH19920712 which covered the same area) Not Considered (NC). However, based on the analyses of the Atlantic group (Tanhua et al., 2010a) the phosphate data of 58JH19940723 were flagged questionable (3). 

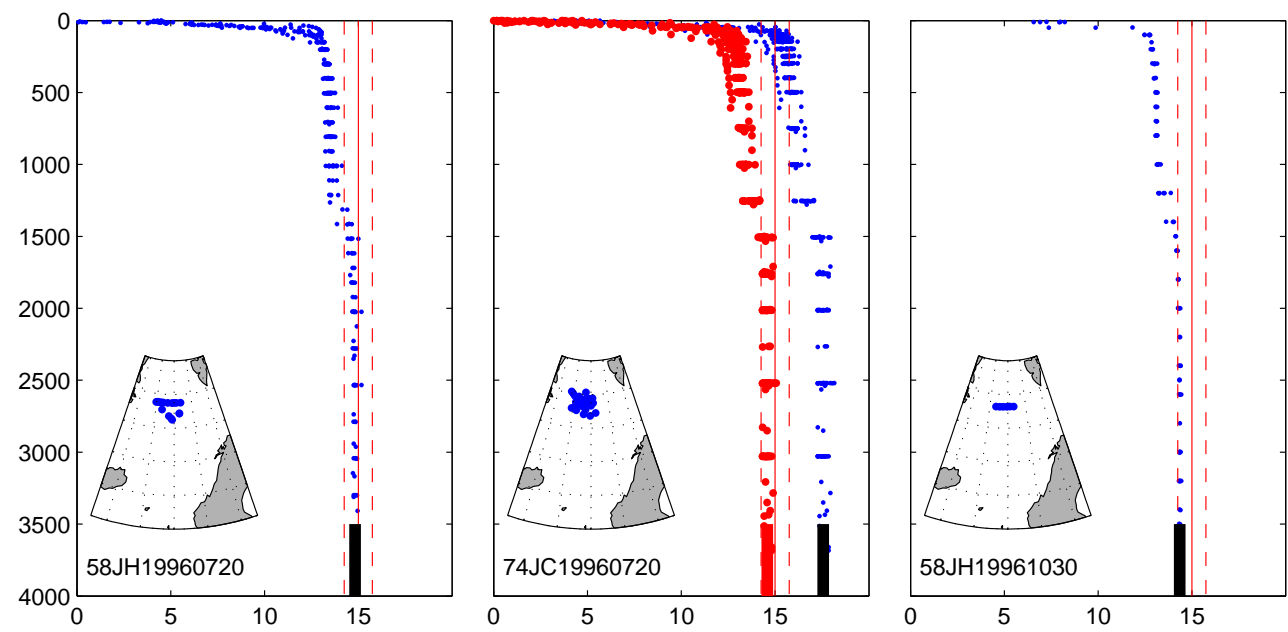

Figure 5. Greenland Sea $\left(73-89^{\circ} \mathrm{N}, 25^{\circ} \mathrm{W}\right.$ to $\left.3^{\circ} \mathrm{E}\right)$ nitrate profiles from $74 \mathrm{JC} 19960720$ with (red) and without (blue) corrections applied, along with data from the previous and subsequent cruises. The thick vertical bars at bottom show mean values deeper than 1900 dbar. For reference, red solid and dashes lines have been drawn at $15 \mu \mathrm{mol} \mathrm{kg}^{-1} \pm 5 \%$.

\section{Cruise 34AR19970805}

This cruise took place mainly in the Denmark Strait which is outside our main crossover area, and for this cruise we adopt the corrections suggested by the Atlantic group (Tanhua et al., 2010a) for phosphate, as well as for the other nutrients.

As for the other offset cruises, the initial assessment of the phosphate data (Table 1) and the distribution of suggested adjustments (Fig. 2) indicate that the offset cruises have too high phosphate data (i.e. significant adjustment factors are less than one). In addition, the depth profiles (not shown) suggested that the errors are affecting the low concentration range in shallow water samples to a greater extent than deep water samples, particularly in spring and summer. The deep waters are without seasonal variations and the errors in those samples are therefore for other reasons. The causes of the errors are most probably related to sample handling, e.g. filtration of photic layer samples or not, analytical procedures such as blank evaluation or instrumentation. We find therefore no justifiable method to adjust these data. Thus, to get a consistent set of data we suggest that the cruises with high values are flagged 3. This applies to the cruises: 58AA19940203, 58AA19940224, 58AA19940826, and 58AA19980308. Other cruises are not adjusted. The recommended phosphate flags are summarized in Table 1.

\subsubsection{Silicate}

For silicate the following 4 cruises fell outside the 5\% limit: 58JH19911105, 58JH19931106, 58AA19940826 and 34AR19970805.

For silicate a complicating factor is the increasing fraction of deep waters from the Arctic Ocean, which has raised silicate concentrations in the deep Greenland Sea (Blindheim and Rey, 2004). This further complicates the evaluation of adjustments, see Sect. 3.3. Evidence of the time trend can be recognised in the inversion results, there is a slight tendency for lower correction factors with time. Taking this into consideration we are reluctant to recommend that adjustments for 58JH19911105 and 58JH19930730 are implemented.

\section{Cruise 34AR19970805}

This cruise took place mainly in the Denmark Strait which is outside our main crossover area, and for this cruise we adopt the corrections suggested by the Atlantic group (Tanhua et al., 2010a).

\section{Cruise 58AA19940826}

The inversion suggested adjustment factor of 0.75. To further evaluate the adjustment factor, the silicate data of 58AA19940826 was compared with data from other cruises. Figure 6 shows these silicate profiles and reveals that there are clear issues with the data from 58AA19940826. The high regime is very high, silicate around $18 \mu \mathrm{mol} \mathrm{kg}{ }^{-1}$, the low range seems reasonable. We suggest that data from this cruise are are flagged 3.

The recommended silicate adjustments are summarized in Table 1.

\section{Consistency of final Nordic Seas nutrient dataset}

In order to evaluate the consistency of the final Nordic Seas nutrient data, a crossover and inversion analysis was carried out on the data with the recommendations implemented. The corrections suggested by the WLSQ inversion are shown in Fig. 2. The dataset appears fairly consistent, except for 

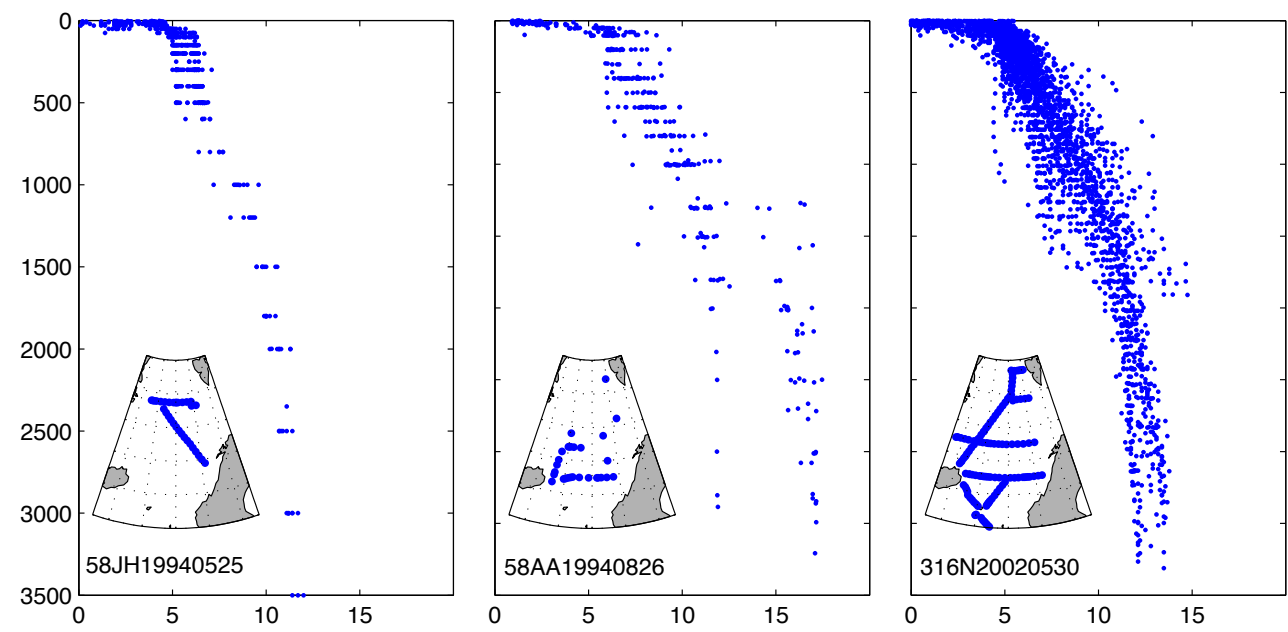

Figure 6. Silicate profiles from 58AA19940826 and two other cruises.

the phosphate data of 58JH19920712 which appear low, this cruise took place over the Greenland Scotland Ridge area and can not be expected to be consistent with the others which were located mainly in the Greenland Sea and the Norwegian Sea, and has been labelled are "NC". The greater hydrographic variability in this region leads to difficulties in the evaluation of adjustments but nevertheless the "NC" data may well be of good quality. The data are hence included in the CARINA data collection.

The inversion suggests differences within $5 \%$ for all variables. This corresponds to $\sim 0.7 \mu \mathrm{mol} \mathrm{kg}^{-1}$ in nitrate, $0.05 \mu \mathrm{mol} \mathrm{kg}{ }^{-1}$ in phosphate and $0.6 \mu \mathrm{mol} \mathrm{kg}{ }^{-1}$ in silicate.

In this work we have concentrated on the differences or anomalies within the collective data. It should also be emphasized, what is apparent from Table 1, that there exists good quality data from the Nordic Seas in different seasons. However, it is clear that in this collection of data there is least consensus on phosphate. The majority of the adjustments suggested for phosphate would result in lower concentrations. Two cruises, in 2002 and 2003, 316N20020530 and 58GS20030922, appear to have good quality data from the Greenland and Iceland Seas. There are, however, indications of systematic differences in phosphate concentrations from these two cruises. The P-N regressions, Table 1, show the former one to have $0.06 \mu \mathrm{mol} / \mathrm{kg}$ higher deep water phosphate than the latter. The intercept value for this cruise, -1.072 , suggests a positive error in the phosphate determination. On the other hand, the 58GS20030922 cruise has overall the lowest phosphate concentrations of the "good" cruises. However, the differences between these two cruises can not be resolved. Both laboratories involved apply quality control procedures in their routines and have participated in interlaboratory exercises such as QUASIMEME (Wells et al., 1997).

It is clear that there are still uncertainties with nutrient data quality that need to be addressed urgently. This issue requires international effort and coordination. In the meantime some measures can be suggested to individual laboratories to improve the precision and accuracy of nutrient analyses, e.g.:

- Subscribe and work according to a laboratory performance programme, e.g. QUASIMEME AQ-1 Nutrients in sea water, http://www.quasimeme.org/.

- Use Certified Reference Materials, CRM, made up in sea water.

- A laboratory reference material, LRM (Aminot and Kérouel, 1998), can be regularly produced and compared to CRMs and QUASIMEME materials. The LRM should be run with each batch of samples.

\section{Data access}

The whole CARINA database is published at http://cdiac. ornl.gov/oceans/CARINA/. Both adjusted and non-adjusted data are available. To disinguish, adjusted data are referred to as data products. We recommend that the community use the data products.sx

The non-adjusted data are available as 188 individual cruise files in comma-separated, WHPO exchange format at http://cdiac.ornl.gov/oceans/CARINA/Carina_table. $\mathrm{html}$. Condensed metadata are contained in the header of each data file and they include the qualify flags assigned during the primary QC. Note that when the nutrient data from a whole cruise were found to be questionable as reported here, they were not necessarily flagged as such in the exchange files.

The data products are available in three merged, comma-separated data files at http://cdiac.ornl.gov/ftp/ oceans/CARINA/CARINA_Database/. One for each of the three CARINA regions, AMS, ATL and SO. All data that were flagged questionable or bad have been excluded from these files and the adjustments that have been motivated in 
the set ot papers in this special issue of ESSD, have been applied.

The adjustments in themselves are accessible through the "Secondary QC and final adjustments for CARINA cruises" link at the CARINA main page, and they can be extracted into a machine readable file.

No special software is needed to access the data, but software for MATLAB users is offered to facilitate reading of the data.

Acknowledgements. The authors appreciate support from Norwegian Research Council through A-CARB (188167) and CARBON-HEAT (185093), from EU IP CARBOOCEAN (511176) and the International Ocean Carbon Coordination Project (IOCCP). We would also like to express our gratitude to R. M. Key at Princeton University, T. Tanhua at Leibniz-Institut für Meereswissenschaften and S. van Heuven at University of Groningen whose extensive efforts made the CARINA project possible. Finally we would like to thank the investigators who collected the data at sea, often during adverse conditions, and contributed their data to the CARINA project. They are identified, whenever possible, in the metadata included in the exchange files. This is contribution no. A304 of the Bjerknes Centre for Climate Research.

Edited by: V. Gouretski

\section{References}

Aminot, A. and Kérouel, R.: Pasteurization as an alternative method for preservation of nitrate and nitrite in sea water samples, Mar. Chem., 61, 203-208, 1998.

Blindheim, J. and Rey, F.: Water-mass formation and distribution in the nordic seas during the 1990s, ICES J. Mar. Sci., 61, 846-863, 2004.

Gouretski, V. V. and Jancke, K.: Systematic errors as the cause for an apparent deep water property variability: Global analysis of the woce and historical hydrographic data, Prog. Oceanogr., 48, 337-402, 2001.

Hansen, B., Østerhus, S., Turrell, W. R., Jónsson, S., Valdimarsson, H., Hátún, H., and Olsen, S. M.: The inflow of atlantic water, heat and salt to the nordic seas across the greenland-scotland ridge, in: Arctic-subarctic ocean fluxes, edited by: Dickson, R. R., Meincke, J., and Rhines, P., Springer, Dordrecht, 15-43, 2008.

Johnson, G. C., Robbins, P. E., and Hufford, G. E.: Systematic adjustments of hydrographic sections for internal consistency, J. Atmos. Ocean. Tech., 18, 1234-1244, 2001.

Jones, E. P., Swift, J. H., Anderson, L. G., Lipizer, M., Civitarese, G., Falkner, K. K., Kattner, G., and McLaughlin, F.: Tracing pacific water in the north atlantic ocean, J. Geophys. Res., 108, 3116, doi:3110.1029/2001JC001141, 2003.

Kasajima, Y., Olsson, K. A., Johannessen, T., Messias, M.-J., Jeansson, E., Bellerby, R. G. J., and Skjelvan, I.: A submesoscale coherent eddy in the greenland sea in 2003, J. Geophys. Res., 111, C07013, doi:10.1029/2005JC003130, 2006.

Key, R. M., Kozyr, A., Sabine, C. L., Lee, K., Wanninkhof, R., Bullister, J. L., Feely, R. A., Millero, F. J., Mordy, C., and Peng, T. H.: A global ocean carbon climatology: Results from global data analysis project (glodap), Global Biogeochem. Cy., 18, GB4031, doi:1029/2004GB002247, doi:1029/2004GB002247, 2004.

Key, R. M., Tanhua, T., Olsen, A., Hoppema, M., Jutterström, S., Schirnick, C., van Heuven, S., Kozyr, A., Lin, X., Velo, A., Wallace, D. W. R., and Mintrop, L.: The CARINA data synthesis project: introduction and overview, Earth Syst. Sci. Data, 2, 105121, doi:10.5194/essd-2-105-2010, 2010.

Olafsson, J., Olafsdottir, S. R., Benoit-Cattin, A., and Takahashi, T.: The Irminger Sea and the Iceland Sea time series measurements of sea water carbon and nutrient chemistry 1983-2008, Earth Syst. Sci. Data, 2, 99-104, doi:10.5194/essd-2-99-2010, 2010.

Olsen, A.: Nordic Seas total dissolved inorganic carbon data in CARINA, Earth Syst. Sci. Data, 1, 35-43, doi:10.5194/essd-1-352009, 2009a.

Olsen, A.: Nordic Seas total alkalinity data in CARINA, Earth Syst. Sci. Data, 1, 77-86, doi:10.5194/essd-1-77-2009, 2009b.

Olsen, A., Key, R. M., Jeansson, E., Falck, E., Olafsson, J., van Heuven, S., Skjelvan, I., Omar, A. M., Olsson, K. A., Anderson, L. G., Jutterström, S., Rey, F., Johannessen, T., Bellerby, R. G. J., Blindheim, J., Bullister, J. L., Pfeil, B., Lin, X., Kozyr, A., Schirnick, C., Tanhua, T., and Wallace, D. W. R.: Overview of the Nordic Seas CARINA data and salinity measurements, Earth Syst. Sci. Data, 1, 25-34, doi:10.5194/essd-1-25-2009, 2009.

Redfield, A. C., Ketchum, B. H., and Richards, F. A.: The influence of organisms on the composition of sea-water, in: The sea, edited by: Hill, M. N., Interscience Publishers, 26-77, 1963.

Ronski, S. and Budeus, G. T.: Time series of winter convection in the greenland sea, J. Geophys. Res., 110, C04015, doi:10.1029/2004JC002318, 2005.

Seber, C. A. F.: Multivariate observations, John Wiley \& Sons, Inc, NJ, 1984.

Stefansson, U.: Dissolved nutrients, oxygen and water masses in the northern irminger sea, Deep-Sea Res., 15, 541-575, 1968.

Tanhua, T., Brown, P. J., and Key, R. M.: CARINA: nutrient data in the Atlantic Ocean, Earth Syst. Sci. Data, 1, 7-24, doi:10.5194/essd-1-7-2009, 2009.

Tanhua, T., Steinfeldt, R., Key, R. M., Brown, P., Gruber, N., Wanninkhof, R., Perez, F., Körtzinger, A., Velo, A., Schuster, U., van Heuven, S., Bullister, J. L., Stendardo, I., Hoppema, M., Olsen, A., Kozyr, A., Pierrot, D., Schirnick, C., and Wallace, D. W. R.: Atlantic Ocean CARINA data: overview and salinity adjustments, Earth Syst. Sci. Data, 2, 17-34, doi:10.5194/essd-2-172010, 2010a.

Tanhua, T., van Heuven, S., Key, R. M., Velo, A., Olsen, A., and Schirnick, C.: Quality control procedures and methods of the CARINA database, Earth Syst. Sci. Data, 2, 35-49, doi:10.5194/essd-2-35-2010, 2010b.

Velo, A., Pérez, F. F., Lin, X., Key, R. M., Tanhua, T., de la Paz, M., Olsen, A., van Heuven, S., Jutterström, S., and Ríos, A. F.: CARINA data synthesis project: $\mathrm{pH}$ data scale unification and cruise adjustments, Earth Syst. Sci. Data, 2, 133-155, doi:10.5194/essd-2-133-2010, 2010c.

Wells, D. E., Aminot, A., De Boer, J., Cofino, W., Kirkwood, D., and Pedersen, B.: A review of the achievements of the eu project 'quasimeme' 1993-1996, Mar. Pollut. Bull., 35, 3-17, 1997. 